\title{
Geologia
}

\section{Litoquímica dos Granitóides da Estrutura em Flor de São Sebastião, São Paulo}

\section{Lithogeochemistry of Granitoids in the São Sebastião Flower Structure, São Paulo}

\author{
Coriolano de Marins e Dias Neto' (coridias@usp.br), Ciro Teixeira Correia' (ccorrei@usp.br), \\ José Manuel Urbano Munhá (jmunha@fc.ul.pt), Colombo Celso Gaeta Tassinari' (ccgtassi@usp.br) \\ 'Departamento de Mineralogia e Geotectônica - Instituto de Geociências - USP \\ R. do Lago 562, CEP 05508-080, São Paulo, SP, BR \\ ${ }^{2}$ Departamento de Geologia - Faculdade de Ciências - Universidade de Lisboa, Lisboa, PT
}

Recebido em 02 de abril de 2008; aceito em 07 de agosto de 2008

Palavras-chave: Complexo Costeiro; Faixa de Dobramentos Ribeira; Ciclo Brasiliano.

\section{RESUMO}

Estudos litoquímicos dos granitóides que ocorrem na região do Complexo Costeiro entre as cidades de Guarujá e São Sebastião, no Estado de São Paulo, são apresentados neste trabalho. Como segmento da Faixa de Dobramentos Ribeira, o Complexo Costeiro na região estudada integra setores com rochas paraderivadas a leste e com rochas ortoderivadas a oeste, organizados segundo uma estrutura de cisalhamento dúctil em flor positiva, cujo eixo se orienta ENE-WSW. Importantes corpos de anfibolitos que ocorrem como "boudins" no interior dos kinzigitos predominantes, acompanham esta orientação. Determinações U-Pb em zircões (SHRIMP I) indicam idade de cristalização de 580 - 590 Ma para os protolitos ígneos dos anfibolitos e de 570 Ma para o ápice do evento metamórfico subseqüente. Os granitóides estudados, presentes no setor ortoderivado, contêm entre 68 e $74 \%$ em peso de $\mathrm{SiO}_{2}$ e correspondem a monzogranitos e granodioritos de afinidade cálcioalcalina. Enclaves máficos de quartzo-monzodioritos localmente presentes nestas rochas posicionam-se por sua vez no campo alcalino. O menor conteúdo em $\mathrm{SiO}_{2}$, assim como as diferentes concentrações de certos elementos traço, como $\mathrm{Zr}$ e Hf, contribuem para a distinção entre os enclaves e suas rochas hospedeiras e sugerem intensa interação química entre os materiais durante a cristalização. O padrão de Terras Raras com baixos teores em Sr, P-Ti e Ta-Nb, em conjunto com a distribuição das amostras no diagrama R1-R2, sugerem um ambiente sincolisional de arco de ilhas na geração destas rochas.

Keywords: Costeiro Complex; Ribeira Fold Belt; Brasiliano Cycle.

\section{ABSTRACT}

The aim of this paper is to present lithochemical data from the granitoids found between Guarujá and São Sebastião in a segment of the Costeiro Complex in São Paulo, State, Brazil. This part of the Ribeira Folded Belt is composed of para-derived rocks on the eastern side, and ortho-derived rocks on the western side of the belt, organized in a ductile shear zone forming a positive flower structure, whose axis runs ENE-WSW. Large boudins of amphibolite occur within predominant kinzigitic gneisses along this axis. The intrusive basic protoliths of the amphibolites have a $580 \mathrm{Ma}$ (U-Pb SHRIMP) crystallization age. $\mathrm{SiO}_{2}$ contents of the granitoids vary between 68 and 74\%, corresponding to monzogranites and granodiorites. Some outcrops display mafic enclaves of quartz-monzodiorites. The granitoids show calc-alkaline affinity while their mafic enclaves tend towards an alkaline affinity. The lower content in $\mathrm{SiO}_{2}$ coupled with coherent differences on some trace element concentrations (e.g. Zr-Hf) contribute to clearly distinguish the enclaves from their country rocks and to suggest intense chemical interaction among the materials during crystallization. The REE pattern, the depletion in Sr, P-Ti, Ta-Nb, and the distribution of the samples on the R1-R2 diagram suggest a syn-collision island arc environment for generation of these rocks. 


\section{INTRODUÇÃO}

Pretendendo estabelecer a evolução crustal e termocronológica do Complexo Costeiro no Estado de São Paulo, Dias Neto (2001) desenvolveu trabalhos visando a caracterização geocronológica, geoquímica e petrográfica dos paragnaisses kinzigíticos e das rochas granitóides, assim como dos núcleos de rochas máficas, que ocorrem deformados e rompidos, no interior de ambos, os quais se constituem nas principais unidades litológicas deste segmento da Faixa de Dobramentos Ribeira.

Os estudos petrográficos, juntamente com os dados de campo, orientaram a escolha das amostras para as análises litoquímicas, comentados em detalhe neste trabalho, as quais forneceram os parâmetros necessários à definição dos ambientes tectônicos relacionados à geração destas rochas.

\section{ÁREA DE ESTUDO}

A área de interesse deste estudo localiza-se na região SE do Estado de São Paulo (Figura 1), entre os paralelos 2330' e $24^{\circ} 00^{\prime} \mathrm{S}$ e meridianos $45^{\circ} 15^{\prime}$ e $46^{\circ} 15^{\prime} \mathrm{W}$, em especial, ao longo dos costões rochosos situados entre as cidades de São Sebastião e Guarujá, onde os tipos litológicos em foco se acham melhor expostos.

\section{O SETOR CENTRAL DA FAIXA DE DOBRAMENTOS RIBEIRA}

\section{Contexto geológico regional}

O Cinturão Móvel Ribeira (Almeida et al., 1973) ou Faixa Ribeira (Cordani et al., 1973) se constitui em um complexo cinturão orogênico que se estende por mais de $1.400 \mathrm{~km}$ ao longo da margem atlântica brasileira. Esta importante unidade geotectônica participou do episódio de colagem, que originou a parte oeste do paleocontinente Gondwana, do Neoproterozóico ao Eopaleozóico (Brito Neves e Cordani, 1991).

Ebert e Hasui (1998) sugerem a geração da Faixa Ribeira durante o Neoproterozóico, juntamente com a Faixa Brasília, através do fechamento em junção tríplice dos blocos Vitória, São Francisco e Paraná. Os processos que orientaram estas colisões se associam a movimentos laterais, oblíquos e frontais, durante a convergência dos blocos, assim como subducção do tipo A.

A região central da Faixa Ribeira, envolvendo o sudeste do Estado de São Paulo, foi compartimentada por Tassinari e Campos Neto (1988), com base em informações geocronológicas, em três domínios tectônicos separados por expressivas zonas de cisalhamento, dispostos, de NW para SE em São Roque, Embu e Costeiro. O Domínio São Roque integra rochas meso a neoproterozóicas que representam uma seqüência meta-vulcanossedimentar de baixo a médio grau, com os grupos Itaberaba na base e São Roque no topo (Juliani et al., 2000; Hackspacher et al., 2000). O Grupo São Roque tem sido interpretado por vários autores (Figueiredo et al., 1982; Bergmann, 1988; Lazzari, 1987; Hackspacher et al., 2000; Tassinari et al., 2001), em termos de ambiente tectônico, como sendo uma bacia sedimentar de retroarco sobre crosta continental. As rochas mais antigas do Domínio Embu forneceram idades de 2,5 Ga com um evento metamórfico em 1,4 Ga, migmatização a 750 Ma e geração de rochas graníticas em 700 - 600 Ma. No Domínio Costeiro as idades das rochas se situam no Neoproterozóico (600 - $650 \mathrm{Ma),} \mathrm{com} \mathrm{plutonismo} \mathrm{tardi} \mathrm{a} \mathrm{pós-tectônico,} \mathrm{de}$ caráter charnockítico, a 550 Ma (Tassinari e Campos Neto, 1988). Resultados K-Ar, em minerais, segundo os autores citados, indicam que o resfriamento regional ocorreu neste domínio entre 500 - $450 \mathrm{Ma}$.

Fonseca et al. (1979), com base na interpretação tectônica dos trabalhos pioneiros de Ebert (1957 e 1968) e Rosier (1965), estenderam os metassedimentos de fácies anfibolito que constituem o Grupo São Roque/Açungui, no Estado de São Paulo, para o Estado do Rio de Janeiro. Neste sentido, o Complexo Embu, definido por Hasui e Sadowski (1976) como o conjunto de rochas paragnáissicas-migmatíticas do Grupo Açungui, se assemelha com os litotipos que compõem o Complexo Paraíba no Estado do Rio de Janeiro, sendo que a relação entre ambos não está bem definida na literatura.

\section{O Domínio Costeiro}

O Domínio Costeiro, no Estado de São Paulo, é delimitado a norte pela Falha de Cubatão e a sul pela linha de costa e ilhas vizinhas (Hasui et al., 1981) (Figura 1). Esta unidade é constituída por três conjuntos litológicos distintos representados por seqüências gnáissico-migmatíticas, para-derivadas e granulíticas (Chiodi et al., 1983; Sobreiro Neto et al., 1983).

O conjunto gnáissico-migmatítico é composto por ortognaisses variados e migmatitos com paleossoma de hornblenda-biotita gnaisse e neossoma de composição granodiorítica.

Os metassedimentos são constituídos, preferencialmente, por rochas síltico-argilosas e, subordinadamente, quartzitos arcosianos e calciossilicáticas. Todo o conjunto paraderivado foi submetido a intenso processo de quartzofeldspatização durante o metamorfismo de médio a alto grau associado ao desenvolvimento do Ciclo Brasiliano, no final do Neoproterozóico.

Núcleos centimétricos a métricos boudinados de rochas máficas-ultramáficas ocorrem no interior dos paragnaisses, como assinalam Coutinho et al. (1991) e Campanha e Ens (1996). Foi descrito por Silva et al. (1977) o Complexo Bairro do Marisco, que representa um corpo de rochas metabásicas com dimensões quilométricas, situado em meio aos parag- 


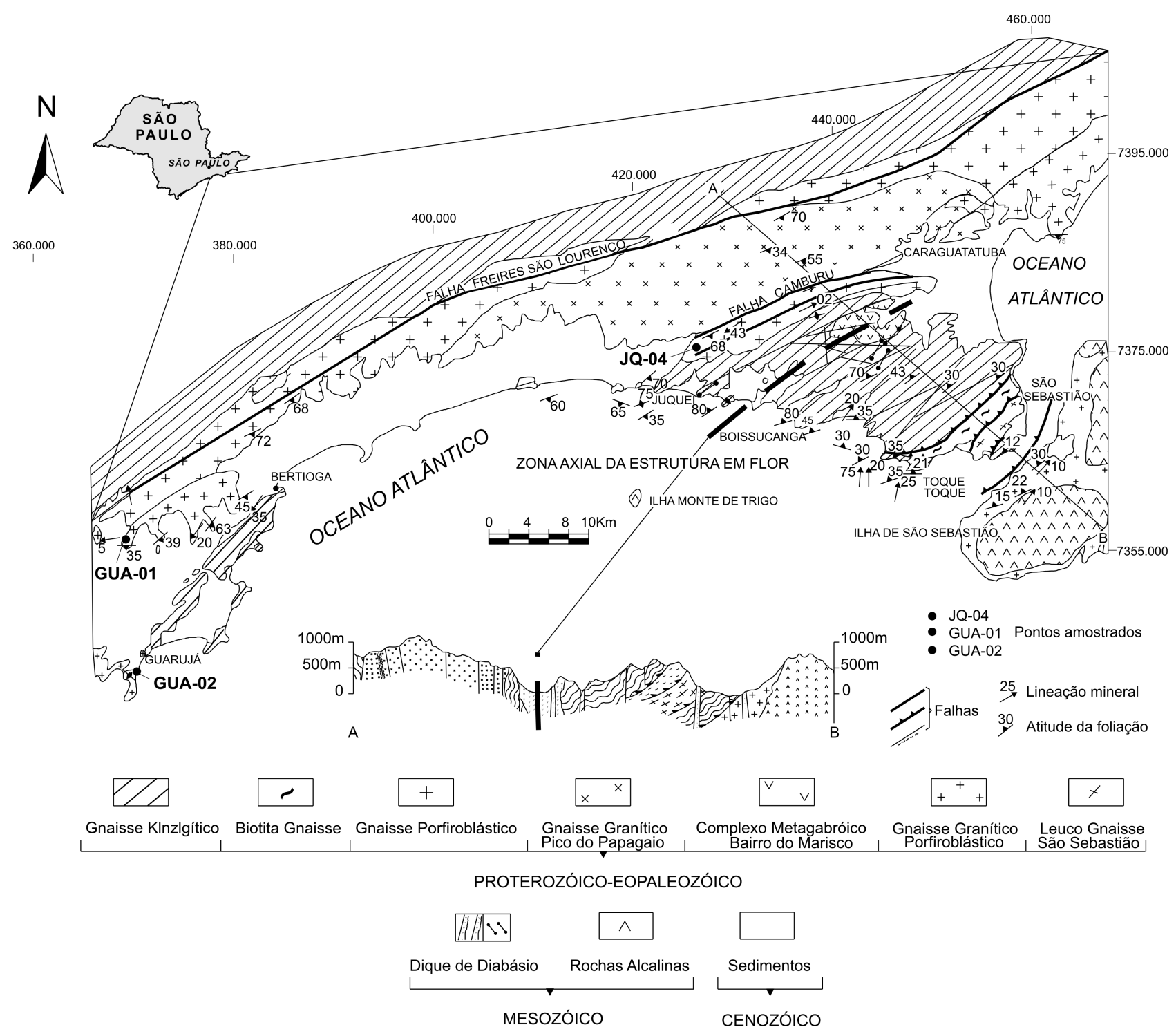

Figura 1. Área estudada - Mapa Geológico-estrutural (Dias Neto, 2001).

naisses com estruturas interpretadas como paleodiques anfibolitizados.

As rochas granulíticas, segundo Chiodi et. al. (1983), são constituídas predominantemente por charnockitos e noritos que ocorrem associados aos gnaisses oftalmíticos e aos corpos graníticos presentes na área. Os charnockitos da área são rochas ígneas que, segundo Tassinari et al. (2000), apresentam gênese relacionada com os processos magmáticos associados aos granitóides que intrudiram as rochas metamórficas do Complexo Costeiro.

Batólitos graníticos, como o de Natividade da Serra e o de Caraguatatuba, e corpos menores, como o charnockito de
Ubatuba, são encontrados no âmbito deste domínio. Na maioria são corpos graníticos porfiríticos, tardi a pós-tectônicos, com composição álcali-cálcica (Janasi e Ulbrich, 1992).

As principais estruturas presentes no Complexo Costeiro, no Estado de São Paulo, definem um "trend” ENEWSW (Chiodi et al., 1983). As rochas metamórficas apresentam uma forte e penetrativa xistosidade e/ou foliação gnáissica, em todas as escalas. Padrões de deformação impostos pelas grandes zonas de cisalhamento NE-SW, que afetaram a região, favorecem figuras anastomosadas que reorientam as estruturas, não raramente, no quadrante NW, como apresentado por Carneiro et al. (1979). Estruturas em 
leque relacionadas às zonas de cisalhamento dúctil, sugerindo regime transpressivo na evolução do Cinturão Ribeira, têm sido assinaladas por diversos autores (Sadowski, 1991; Ebert, Hasui, Costa, 1991; Machado e Endo, 1993; Campanha e Ens, 1993; Ebert et al., 1993; Ebert e Hasui, 1998; Dias Neto et al., 2006).

O Complexo Costeiro, durante o Mesozóico, foi afetado por expressiva atividade magmática alcalina relacionada ao processo de fragmentação continental e de abertura do Oceano Atlântico. Determinações K-Ar obtidas para complexos alcalinos forneceram idades dentro do intervalo de 95 e 45 Ma (Amaral et al., 1967; Ulbrich e Gomes, 1981), enquanto que para os diques de diabásio, normalmente concordantes com o "trend" regional e muito freqüentes no interior do complexo, as idades obtidas situaram-se no intervalo de 140 - 110 Ma (Minioli, 1971).

Expressivos movimentos verticais ocorreram na área durante o Cenozóico associados à abertura do Atlântico Sul, condicionando escarpas de falhas e favorecendo fortes processos erosivos, expondo rochas de níveis crustais profundos.

\section{O COMPLEXO COSTEIRO NA ÁREA DE ESTUDO}

O Complexo Costeiro na região estudada integra setores com rochas paraderivadas a leste e com rochas ortoderivadas a oeste, organizados segundo uma estrutura de cisalhamento dúctil em flor positiva, cujo eixo se orienta ENE-WSW (Dias Neto et al., 2006). Importantes corpos de anfibolitos, que ocorrem como "boudins" no interior dos kinzigitos predominantes, acompanham esta orientação.

Enquanto o domínio paraderivado encontra-se melhor representado na península de São Sebastião, os litotipos ortoderivados concentram-se no setor W-NW da área, entre as localidades de Juqueí e Guarujá (Figura 1).

\section{Unidade dos paragnaisses}

Os paragnaisses são rochas relativamente heterogêneas que acompanham as variações típicas de uma seqüência metassedimentar. Estruturas migmatíticas com injeções de material neossomático quartzo-feldspático apresentando foliação, quando geradas em condições dinâmicas, ou pegmatóides, quando tardias, são comuns.

O bandamento gnáissico é irregular, refletindo os processos dinâmicos e migmatíticos que acompanharam a geração destas rochas, onde núcleos amendoados de litotipos mais antigos (gnaisses kinzigíticos, restitos biotíticos, rochas calciossilicáticas e rochas anfibolíticas) são contornados pela foliação definida pela orientação de biotita, em especial, e de sillimanita, quando presente, evidenciando o processo de transposição a que foram submetidas.
As texturas variam de lepidoblástica a granoblástica, com granulação de média a grossa, onde a recuperação de grãos é bastante comum e os grãos de quartzo e feldspato apresentam extinção ondulante. A rocha gnáissica é constituída basicamente de plagioclásio-sódico, quartzo e biotita.

\section{Unidade dos ortognaisses e dos granitóides orientados}

No setor W-NW da área de estudo configura-se o domínio ortoderivado, em contato gradacional com os paragnaisses na localidade de Juqueí (Silva et al., 1977; Maffra, 2000), onde ocorrem rochas de composição granítica, contendo cerca de 30\% de quartzo, 20\% de microclínio, 20\% de plagioclásio e $20 \%$ de biotita. Os acessórios mais comuns são apatita, zircão e opacos. A textura blastomilonítica com os grânulos de quartzo estirados e recristalizados acompanham a biotita e o feldspato organizados em faixas. Os porfiroblastos, em especial de feldspato potássico, em forma de olhos, ocorrem em grande quantidade ao longo da foliação, justificando a designação, atribuída por Maffra (2000), de “augen” gnaisse Juqueí (JQ04 - Figura 1). Cloritização de biotitas indica um processo retrometamórfico sobre estas rochas.

Estes gnaisses ortoderivados estão em contato tectônico, através da falha de Camburu, com o granito porfirítico Pico do Papagaio (Campanha e Ens, 1996), cuja composição monzogranítica contempla quartzo, plagioclásio, microclínio, biotita e hornblenda. Porções indeformadas, interiores ao corpo granítico, com fenocristais idiomórficos de feldspato potássico, gradam para faixas onde estes minerais estão ovalados e lenticularizados, passando para uma rocha intensamente deformada na zona de cisalhamento, o que aponta para um posicionamento tardi-tectônico deste maciço.

Os “augen” gnaisses, descritos por Maffra (2000), acompanham os contrafortes da Serra do Mar, no sentido SW, estendendo-se até a região de Bertioga/Piaçagüera (Silva et al., 1977). Essas rochas foram descritas por Janasi e Ulbrich (1992) como rochas ortoderivadas blastomiloníticas, descritas como hornblenda-biotita gnaisse granitóide porfiróide (GUA01 - Figura 1), com mineralogia básica representada por cerca de 35\% de microclínio, 35\% de quartzo, 25\% de plagioclásio e 15\% de biotita, com alguma hornblenda. Observa-se, em lâmina delgada, forte recristalização em regime dúctil. Núcleos lenticularizados de composição quartzo-monzodiorítica ocorrem no interior dos ortognaisses, contendo, aproximadamente $40 \%$ de plagioclásio, 25\% de hornblenda, 25\% de biotita e alguns percentuais de quartzo e como acessórios apatita, titanita, opacos e zircão. Alguns cristais de feldspato potássico se destacam na matriz intensamente orientada. A textura presente é granoblástica, com recuperação de grãos, onde 
plagioclásio e quartzo lenticularizados se apresentam recristalizados e em equilíbrio. Nas bordas dos núcleos a rocha se encontra muito foliada, com a granulação mais fina, registrando os efeitos do cisalhamento dúctil a que foi submetida, juntamente com a rocha granítica.

No limite Sul da região investigada, na Ponta das Galhetas, área urbana do município do Guarujá, ocorrem rochas graníticas tardi-tectônicas, levemente orientadas (GUA02 - Figura 1). Predominam texturas porfiríticas, com fenocristais de feldspato potássico e granulação média a grossa, tendo como mineralogia básica, aproximadamente, $35 \%$ de quartzo, 25\% de plagioclásio, 20\% de biotita e 15\% de microclínio, com os acessórios apatita, opacos e zircão. Janasi e Ulbrich (1992) o denominam biotita-granito gnáissico porfirítico. O quartzo apresenta início de recristalização e extinção ondulante. A orientação da rocha é dada pela ordenação do feldspato potássico e das lentes de quartzo, acompanhando os minerais micáceos. Este corpo granítico contém enclaves de dezenas de metros de dimensão, de granulação média, também levemente orientados, com composição diorítica. Cerca de $45 \%$ de plagioclásio, $25 \%$ de biotita e $20 \%$ de hornblenda representam os minerais principais, enquanto titanita e apatita são acessórios muito comuns, e zircão e opacos ocorrem de modo menos freqüente. Os raros grãos de quartzo, quando presentes, e o plagioclásio apresentam extinção ondulante.

\section{AMOSTRAGEM E PROCEDIMENTOS ANALÍTICOS}

A amostragem foi feita ao longo da costa ou nos cortes das estradas face à melhor qualidade dos afloramentos e de preservação dos litotipos. Procurou-se amostrar em cada afloramento a diversidade dos litotipos presentes, seja da rocha principal, seja dos enclaves. Desse modo, foram selecionados para análises químicas três conjuntos distintos de rochas ortoderivadas. Na localidade de Juqueí, os ortognaisses desprovidos de enclaves. No Guarujá, os “augen” gnaisses descritos por Maffra (2000) (GUA01) e o corpo granítico orientado da Ponta das Galhetas (GUA02), ambos com enclaves.

Amostras designadas como JQ04A foram coletadas ao longo da Rodovia Rio-Santos, em Juqueí (Figura 1). Na confluência desta rodovia com a estrada Piaçagüera-Guarujá, foram coletadas as rochas GUA01, enquanto as GUA02 foram amostradas na Ponta das Galhetas, no Guarujá. Os afloramentos graníticos GUA apresentam enclaves, de composição monzodiorítica, cujos resultados analíticos serão tratados em conjunto com os granitóides associados.

No total foram preparadas e encaminhadas para análise 12 amostras de rochas graníticas (5 do afloramento JQ04, 4 do afloramento GUA01, 3 do afloramento GUA02 e 7 enclaves monzodioríticos ( 2 do afloramento GUA01 e 5 do afloramento GUA02).

Para evitar contaminação das amostras, optou-se pela utilização de prensa hidráulica, moinho de ágata e micronizador de ágata para pulverização. $\mathrm{O}$ material pulverizado foi enviado ao Laboratório ACT LABS (Canadá) para quantificação de elementos maiores, traços e ETR. Os resultando obtidos encontram-se na Tabela 1 . Os elementos maiores foram analisados (em óxidos) por fusão e digestão total em Plasma de Indução Acoplado (ICP), cujo limite de detecção é $0,01 \%$. Os elementos traços e os ETR foram analisados por ICP-MS. O controle da precisão e acurácia das análises foram controlados pela leitura dos seguintes padrões internacionais: STM1, MAG1, BIR1, DNC1, SY3 e GXR1, cujos resultados indicam desvios em relação aos valores certificados, que em geral não excedem a 5\%.

\section{GEOQUÍMICA DE ROCHAS}

As rochas graníticas JQ04A e GUA possuem teores de $\mathrm{SiO}_{2}$ variando entre 68 e $74 \%$ e se localizam nos campos dos monzogranitos (GUA) e granodioritos (JQ), enquanto os enclaves máficos, dos afloramentos GUA, com 46 a $57 \%$ de $\mathrm{SiO}_{2}$, são classificados como quartzo-monzodioritos, segundo o diagrama QAP (Figura 2) de Le Maitre (1989).

Quando posicionadas nos diagramas de Irvine e Baragar (1971), as rochas GUA e JQ04 se enquadram como séries cálcio-alcalinas (Figura 3), sendo que as graníticas se apresentam como subalcalinas, e os enclaves máficos com tendência alcalina (Figura 4), ou, no caso das amostras GUA01, no limite entre os campos.

Enquanto os termos graníticos estudados se enquadram no limiar entre o caráter fracamente metaluminoso (GUA01) e peraluminoso (GUA02 e JQ04A), no diagrama de Maniar e Piccoli (1989), com índice de Shand ao redor de 1 (Figura 5), os dioríticos se apresentam francamente metaluminosos.

Os diagramas de Harker para os elementos maiores (Figura 6) evidenciam a impossibilidade de individualização clara entre os três conjuntos graníticos, os quais se aglomeram em torno de $70 \%$ de $\mathrm{SiO}_{2}$. Pequenos indícios de separação podem ser observados com relação aos maiores teores de $\mathrm{MgO}$ e $\mathrm{Na}_{2} \mathrm{O}$, e menores em $\mathrm{K}_{2} \mathrm{O}$, para as rochas graníticas JQ04A. Os menores teores de $\mathrm{CaO}$ ocorrem nas amostras graníticas GUA02. Os termos monzodioríticos das amostras GUA02 retratam melhor o fracionamento, mostrando correlações positivas entre $\mathrm{SiO}_{2}$ e $\mathrm{Al}_{2} \mathrm{O}_{3}, \mathrm{~K}_{2} \mathrm{O}$ e $\mathrm{Na}_{2} \mathrm{O}$, e negativas para os demais óxidos. Os diagramas mostram que as tendências do comportamento geoquímico dos enclaves e das rochas graníticas são coerentes para a maioria dos óxidos representados, à exceção do comportamento do $\mathrm{P}_{2} \mathrm{O}_{5}$ e TiO para os enclaves GUA01. Os padrões coerentes podem su- 


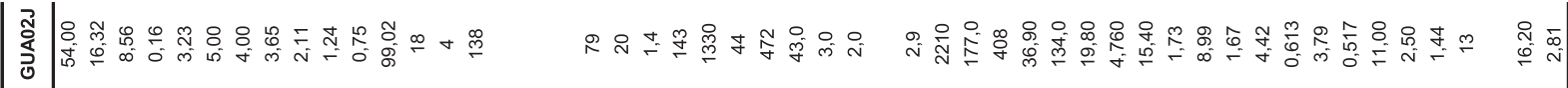

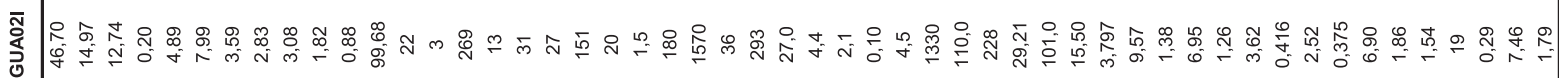

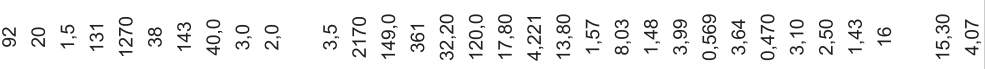

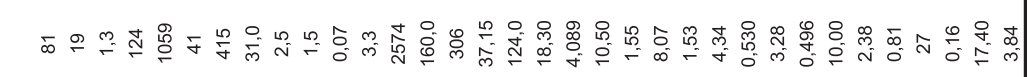

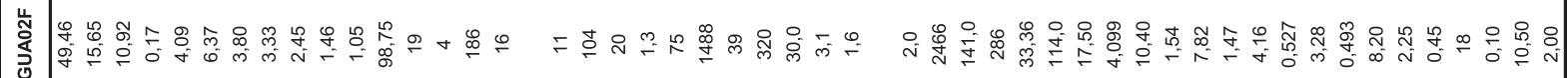

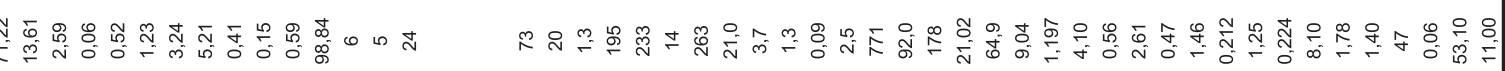

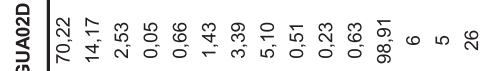

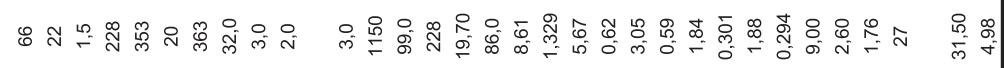

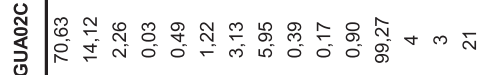

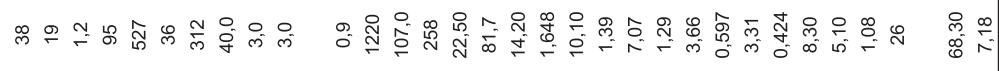

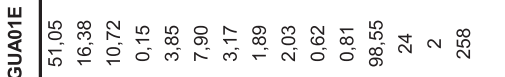

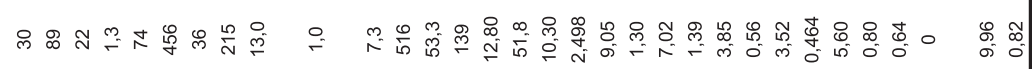

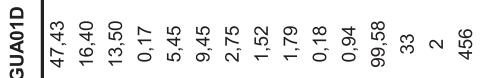

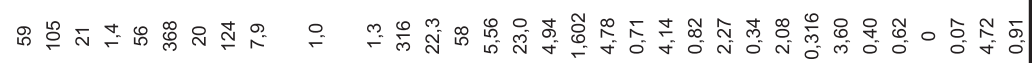

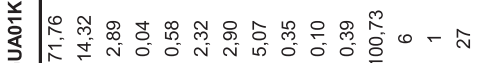

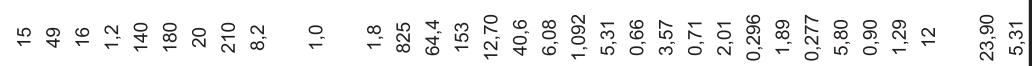

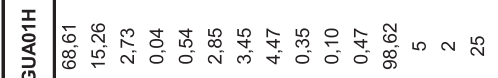
N

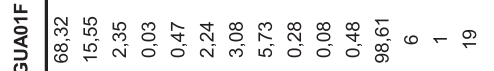

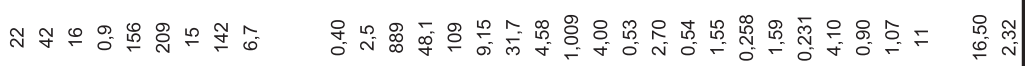

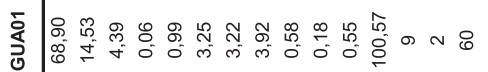

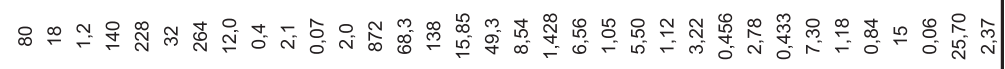

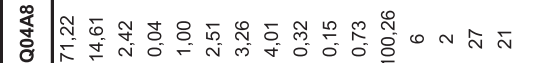

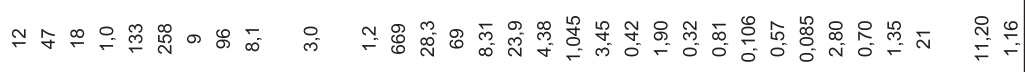

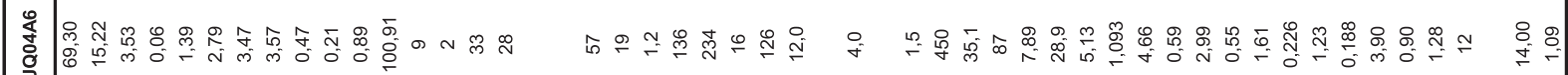

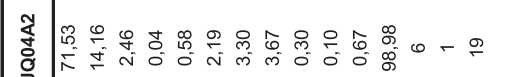

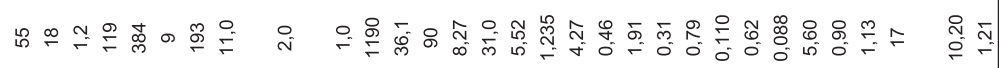

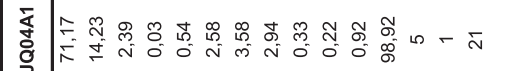

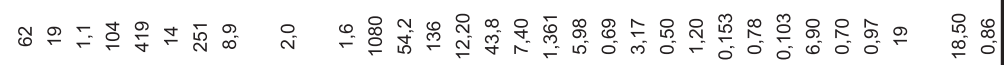

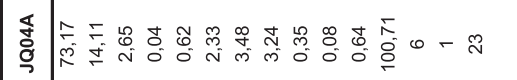

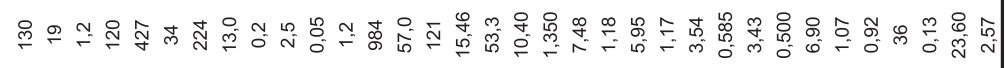

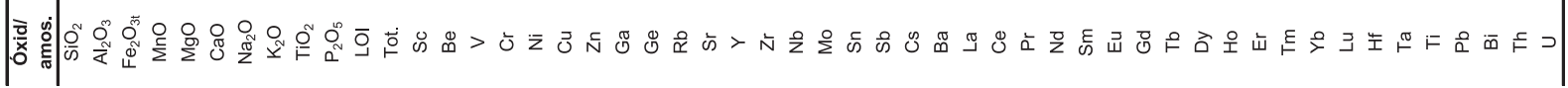


gerir que estejam geneticamente relacionadas ou tenham sofrido intensa interação entre si.

Os diagramas de variação Harker para os elementos traços (Figura 7) também não permitem individualizar, no geral, os três corpos graníticos analisados. Com relação aos enclaves monzodioríticos, os elementos incompatíveis $\mathrm{Zr}$, Hf, Nd, Ba, Rb e Sr permitem a separação das amostras GUA02, com maiores teores, e GUA01, com teores menores. No confronto entre o comportamento destes elementos nos enclaves e nos granitóides, observa-se que os enclaves apresentam concentrações equivalentes (Zr, Hf e Rb), ou que superam os conteúdos dos granitóides encaixantes $(\mathrm{Nd}$, $\mathrm{Ba}, \mathrm{Sr}, \mathrm{V}$ e Y), em particular no caso dos enclaves GUA2. Estas características sugerem que não existem relações comagmáticas entre os enclaves GUA1 e GUA2 e, também, entre os enclaves e suas encaixantes granitóides.

A possibilidade de que esse comportamento geoquímico seja resultante de intensas interações geoquímicas, entre os enclaves e suas encaixantes, é pouco provável, uma vez que o teor em elementos incompatíveis dos enclaves mais básicos supera o das encaixantes (notadamente para Sr, V e Y).

Quanto aos granitóides, merece destaque o proeminente enriquecimento em Th quando comparados com a média de 10,7 ppm para a crosta superior pós-arqueana (Taylor e MacLennan, 1985), sendo que as rochas GUA02, além de apresentar 4 vezes este valor, também se acham com elevados valores de U (5 a 11 ppm), quando a média na crosta superior é 2,8 ppm, segundo os autores citados.

Os padrões de distribuição dos ETR para os corpos graníticos apresentam-se fracionados, com variações no empobrecimento das TR pesadas, entre os três conjuntos de amostras graníticas, cujas assinaturas geoquímicas se aproximam entre si. Comparativamente, as rochas JQ04A (Figura 8a) são mais pobres em ETR e apresentam a maior variação no fracionamento das TR pesadas ( $\mathrm{La} / \mathrm{Yb}$ entre 11 e 47; enquanto a mesma razão corresponde a 16 - 28 e 21 - 50 respectivamente para GUA1 e GUA2). Com um conjunto de amostras mais homogêneo e um padrão menos fracionado, as rochas GUA01 apresentam menor realce nas anomalias de $\mathrm{Eu}$ (Eu/Eu* entre 0.58 - 0.72, enquanto a mesma relação situa-se entre 0.47 - 0.82 e 0.42 - 0.60, respectivamente para JQ04A e GUA02). Os maiores teores de ETR são das amostras GUA02, as quais apresentam o padrão mais fracionado nas TR leves. A distribuição dos ETR dos enclaves GUA01, mais ricos e mais fracionados que GUA02 (Figura 8b), revelam sutis anomalias negativas de Eu (razões Eu/Eu* entre 0.79 - 1.01 para GUA01 e entre 0.82 - 0.95 para GUA02) e padrões mais fracionados (em particular quanto aos ETR leves) que suas encaixantes. Quando comparados entre si, os enclaves GUA02 mostram destacado maior enriquecimento nos ETR leves (razões La/Yb entre

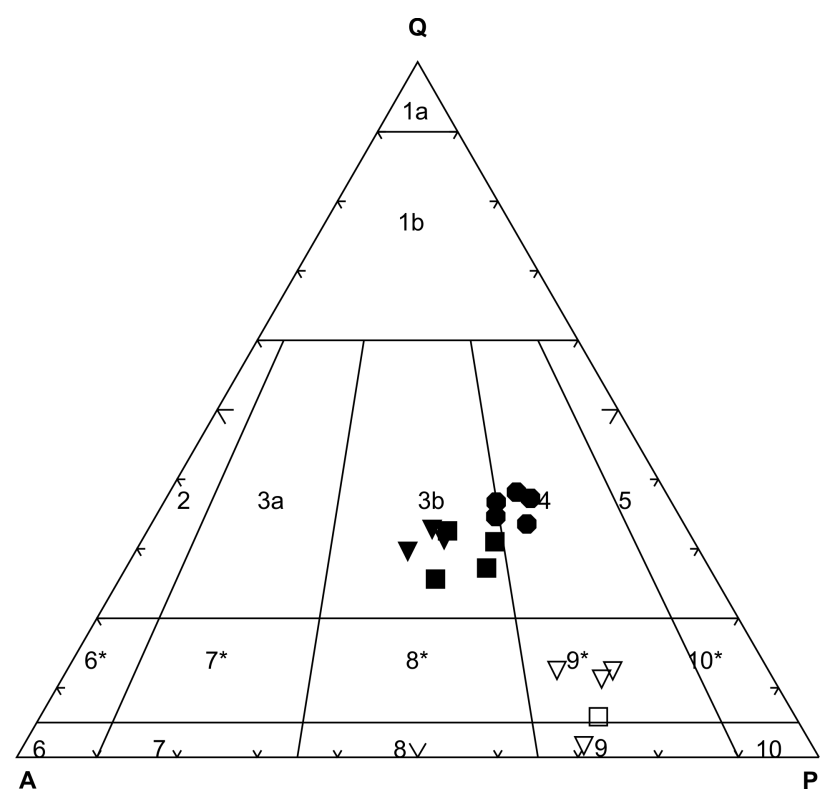

Figura 2. Classificação das rochas graníticas no diagrama QAP normativo de Le Maitre (1989). Círculos cheios representam os ortognaisses de Juqueí (JQ04A); triângulos e quadrados cheios retratam, respectivamente, os granitóides orientados da Ponta das Galhetas (GUA02), no Guarujá, e os ortognaisses da confluência entre as rodovias Piaçagüera e Rio-Santos (GUA01). Os enclaves dioríticos destas duas últimas litologias estão representados por triângulos e quadrados vazios. 3b - monzogranito; 4 - granodiorito; 9* - quartzo-monzodiorito; 9 - monzodiorito.

27 - 32) com relação ao padrão correspondente de GUA01 (razões La/Yb entre 7 - 11).

Assim, de modo similar ao indicado pelo comportamento dos elementos traços, os padrões dos ETR sugerem possíveis magmas distintos para os enclaves GUA01 e GUA02, e que esses magmas não se vinculam geneticamente aos magmas mais evoluídos que teriam produzido suas encaixantes.

Os três conjuntos de rochas granitóides em análise também apresentam padrões semelhantes de distribuição das concentrações dos demais elementos traços, quando normalizados pelos valores de Pearce (1983), e revelam proeminentes anomalias negativas de Ta-Nb que, segundo Condie (1989), são características comuns a rochas geradas em ambientes de arco magmático. Rochas formadas nesses ambientes, em geral, também portam anomalias negativas de $\mathrm{Sr}, \mathrm{Pe}$ Ti e são enriquecidas em LILE, características estas também presentes nos granitóides em foco.

As rochas JQ04, GUA01 e GUA02 parecem representar materiais sin-colisionais a julgar por seus posicionamentos no diagrama $\mathrm{R}_{1} \times \mathrm{R}_{2}$ (Figura 9) de Batchelor e Bowden (1985). 


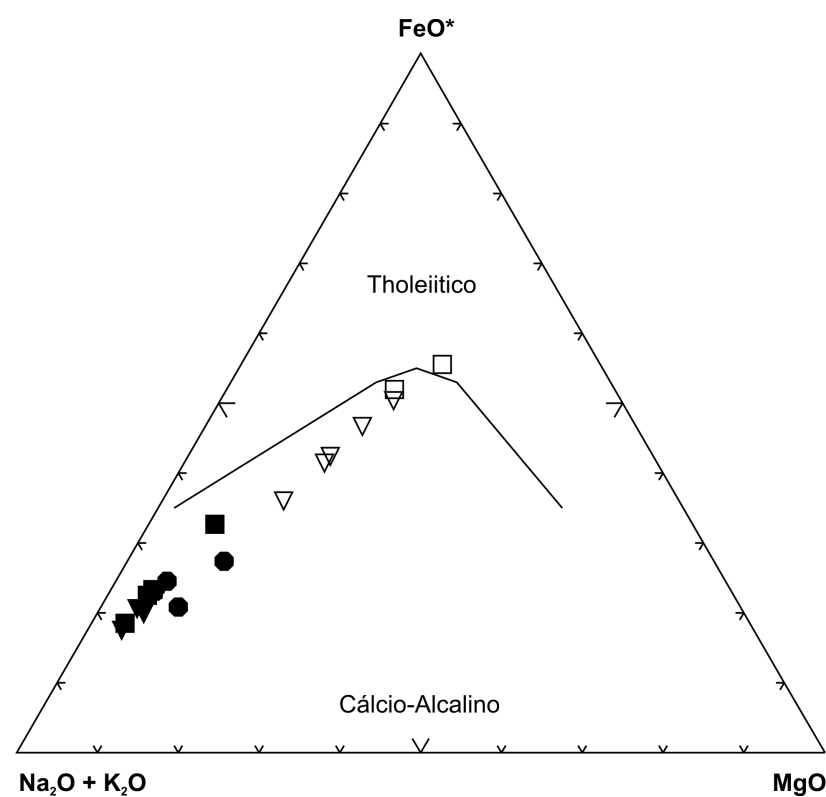

Figura 3. Diagrama AFM de Irvine e Baragar (1971), para as rochas graníticas e os enclaves. Os símbolos acompanham a Figura 2.

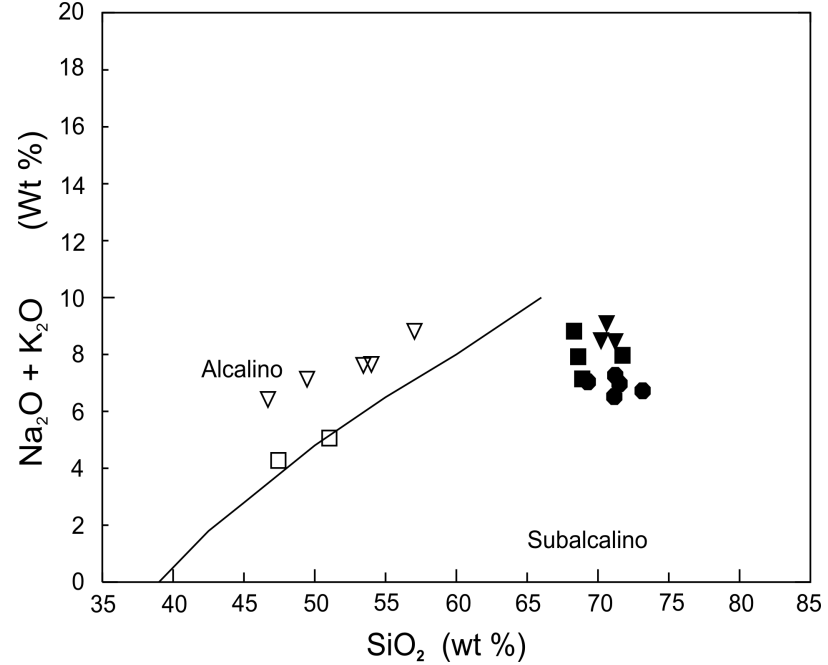

Figura 4. Diagrama sílica x álcalis, segundo Irvine e Baragar (1971), para as rochas graníticas e os enclaves. Os símbolos acompanham a Figura 2.

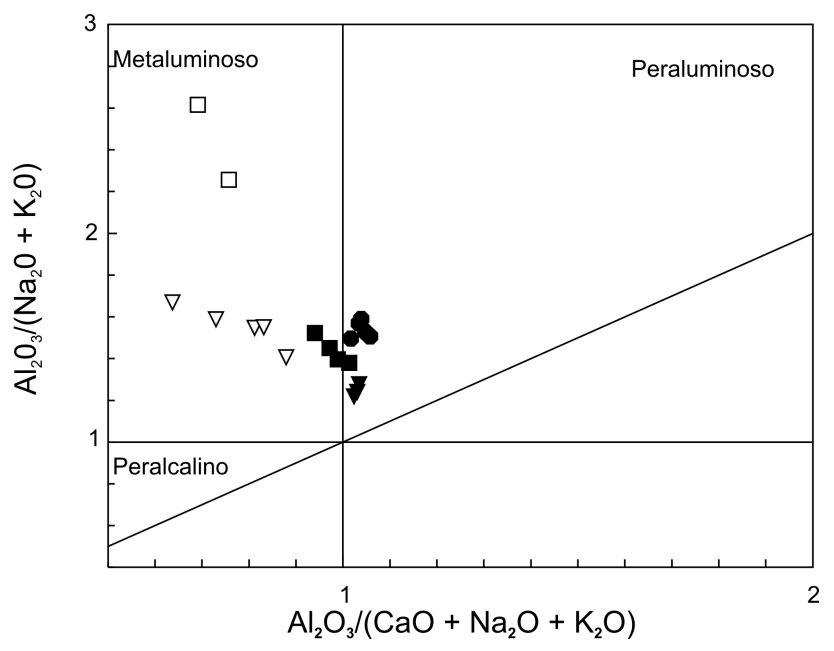

Figura 5. Diagrama de alumina-saturação, segundo Maniar e Piccoli (1989), para as rochas graníticas e os enclaves. Os símbolos acompanham a Figura 2. 

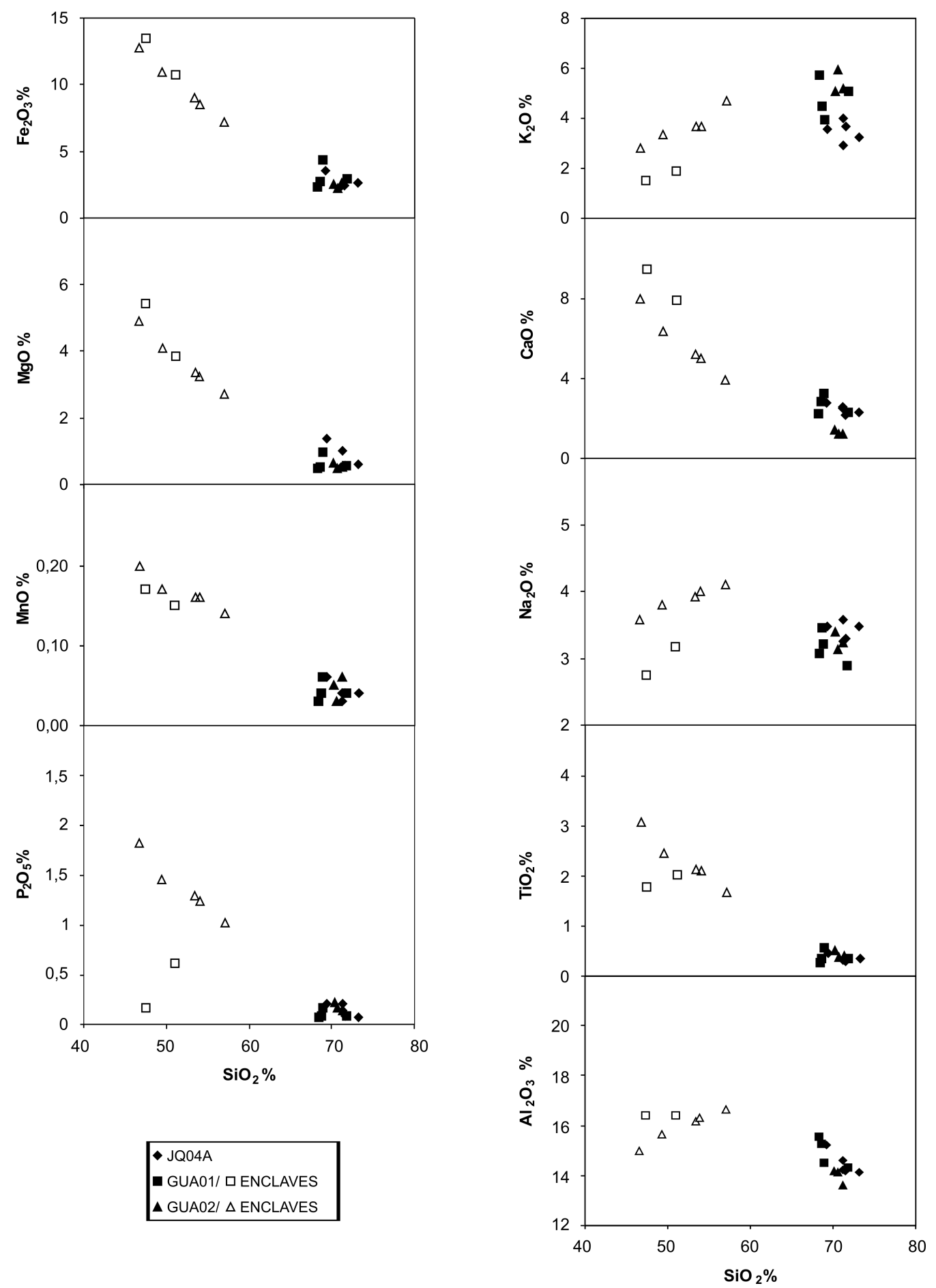

Figura 6. Diagramas de Harker, para os elementos maiores, com os ortognaisses de Juqueí (JQ04A), em losangos cheios; os ortognaisses da confluência das rodovias Piaçagüera/RioSantos (GUA01), em quadrados cheios; e os granitos orientados da Ponta das Galhetas (GUA02), em triângulos cheios; com enclaves respectivos em símbolos vazios. 

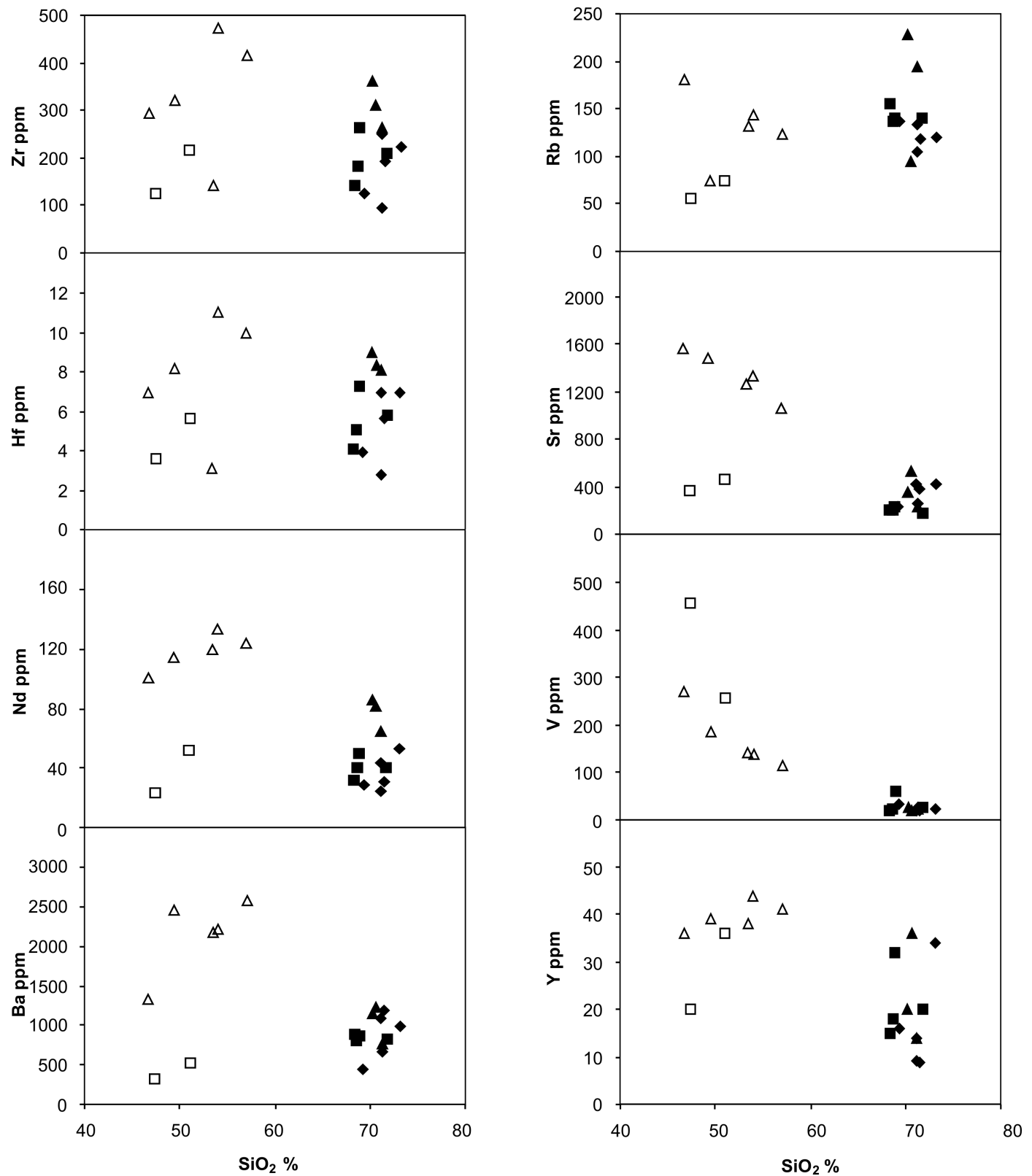

Figura 7. Diagramas de Harker, para os elementos traços, com a legenda acompanhando a Figura 6. 

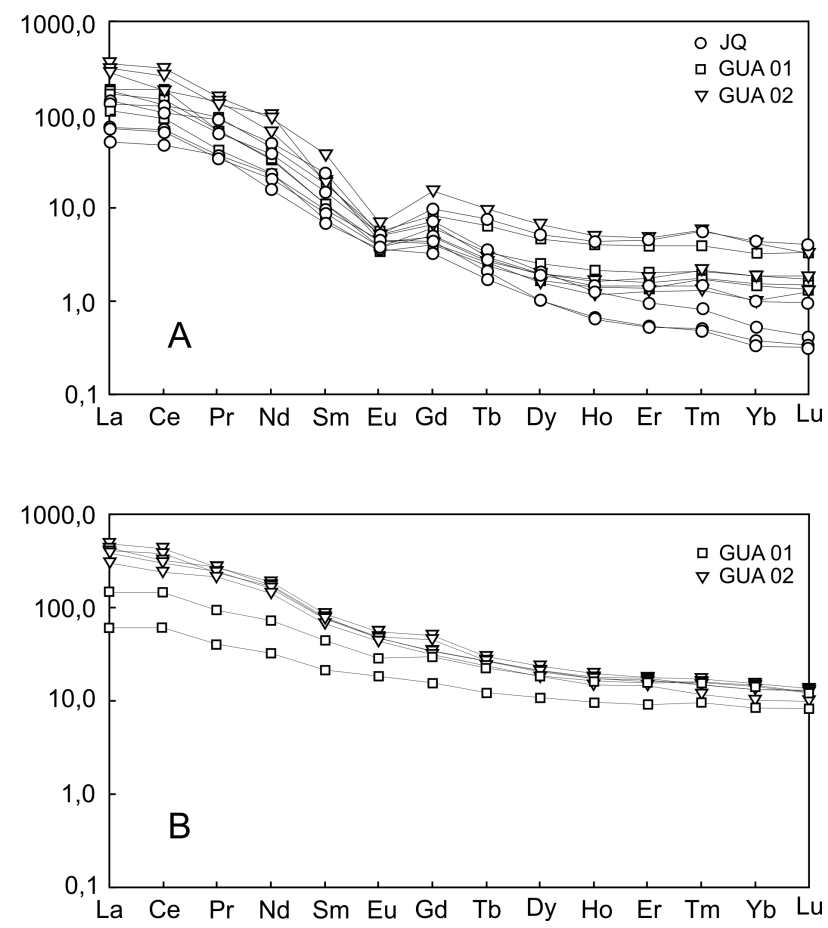

Figura 8. Diagramas de concentrações normalizadas para condrito (Evensen et al., 1978) de ETR. A. Ortognaisses de Juqueí (JQ04A), ortognaisses da Piaçagüera/Rio-Santos (GUA01) e granitos orientados da Ponta das Galhetas (GUA02), Guarujá. B. Enclaves monzodioríticos que ocorrem no interior dos ortognaisses GUA01 e GUA02.

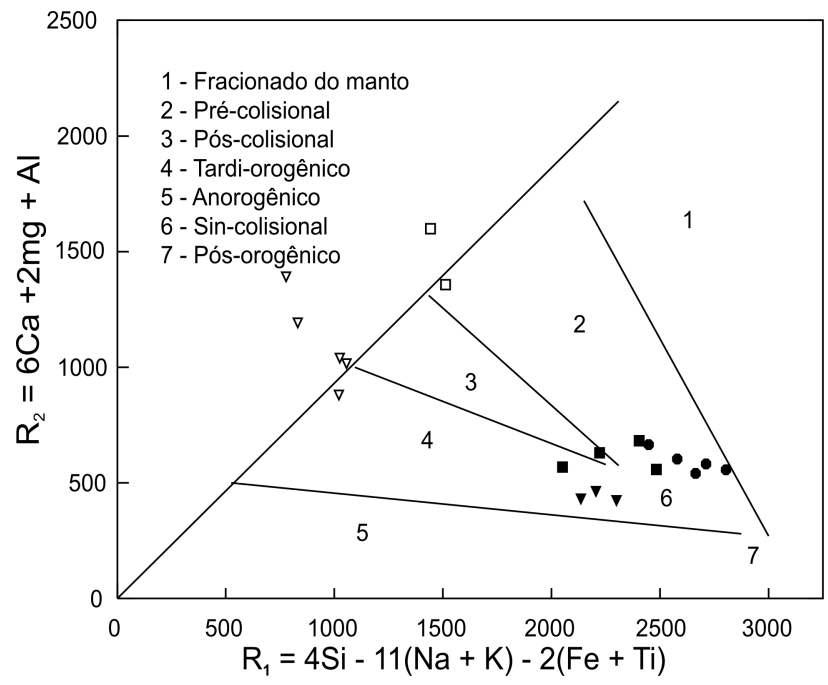

Figura 9. Posicionamento em diagrama R1 x R2 (Batchelor e Bowden, 1985) das rochas graníticas e dos enclaves estudados. Os símbolos acompanham a Figura 2.

\section{CONSIDERAÇÕES FINAIS}

Os granitóides do setor ortoderivado estudados contêm entre 68 e 74\% de $\mathrm{SiO}_{2}$, correspondendo a monzogranito e granodiorito. Enclaves máficos de quartzo-monzodioritos estão presentes. Enquanto os corpos granitóides se apresentam com afinidade cálcio-alcalina, os enclaves máficos se posicionam no campo alcalino.

O caráter mais básico dos dois conjuntos de enclaves e o padrão mais enriquecido destas rochas em elementos traços incompatíveis, como Ba, Sr e Y, quando comparados com as suas encaixantes, indicam sua derivação a partir de magmas distintos daquele responsável pela formação das rochas hospedeiras. Quando comparados entre si, as discrepâncias notadas no conteúdo dos elementos traços também indicam prováveis fontes distintas para os dois conjuntos de enclaves. Os padrões de ETR dos granitóides são coerentes com possíveis magmas distintos para os dois conjuntos de enclaves e também indicam que esses magmas não se vinculam, geneticamente, aos magmas mais evoluídos que teriam produzido as suas encaixantes.

O padrão de Terras Raras e o padrão de anomalias negativas em Sr, P-Ti e Ta-Nb, em conjunto com a distribuição das amostras no diagrama R1-R2 (Figura 9), sugerem um ambiente sincolisional de ilhas em arco na geração destas rochas.

Essa possibilidade é coerente com o quadro evolutivo proposto por Dias Neto (2001), onde as rochas desta região estariam ambientadas em uma posição de bacia de retroarco no intervalo do Neoproterozóico - Eocambriano, durante o regime de convergência que estaria gerando o supercontinente Gondwana. Esse arco magmático teria evoluído em uma época pouco anterior, há 600 Ma, não tendo sido ainda localizadas, na área de estudo, rochas graníticas diferenciadas do manto superior, no Neoproterozóico, que possam representar um arco magmático juvenil neste período de tempo.

Neste contexto, os ortognaisses do presente estudo com idade isocrônica $\mathrm{Rb}$-Sr, em rocha total de aproximadamente $630 \mathrm{Ma}$ (Dias Neto, 2001), e valores de $\varepsilon_{\mathrm{Nd}}$ calculados para $630 \mathrm{Ma}$, entre -6 e -7 , poderiam caracterizar um arco magmático produzido por processos de fusão parcial de rochas continentais pré-existentes.

\section{REFERÊNCIAS BIBLIOGRÁFICAS}

ALMEIDA, F. F. M. DE; AMARAL, G.; CORDANI U. G.; KAWASHITA, K. The precambrian evolution of the South American Cratonic Margin south of Amazonas River. In: NAIRN, A. E. M.; STEHLI, F. G. (Ed.). The ocean basin and margins. New York: Plenum Press, 1973. p. 411-446. v. 1.

AMARAL, G.; BUSHEE, J.; CORDANI, U. G; KAWASHITA, 
K.; REYNOLDS, J. H. Potassium-argon age of alkaline rocks from southern Brazil. Geochimica et Cosmochimica Acta, v. 31, p. 117-142, 1967.

BATCHELOR, R. A.; BOWDEN, P. Petrogenetic interpretation of granitoid rocks series using multicationic parameters. Chemical Geology, v. 48, p. 43-55, 1985.

BERGMANN, M. Caracterização estratigráfica e estrutural da seqüencia vulcano-sedimentar do Grupo São Roque, na região de Pirapora do Bom Jesus, estado de São Paulo. 1988. 166 f. Dissertação (Mestrado) - Instituto de Geociências, Universidade de São Paulo, São Paulo, 1988.

BRITO NEVES, B. B.; CORDANI, U. G. Tectonic evolution of South America during late proterozoic. Precambrian Research, v. 33, p. 23-40, 1991.

CAMPANHA, G. A. C.; ENS, H. H. Estrutura geológica na região de São Sebastião. In: SIMPÓSIO DE GEOLOGIA DO SUDESTE, 3., 1993, Rio de Janeiro. Boletim de Resumos... Rio de Janeiro: SBG, 1993. p. 51- 52.

CAMPANHA, G. A. C.; ENS, H. H. Estruturação geológica da Serra de Juqueriquerê, São Sebastião, SP. Boletim Instituto de Geociências. Série Cientifica, v. 27, p. 1-15, 1996.

CARNEIRO, C. D. R.; SANTORO, E.; RODRIGUES, E. P.; HASUI, Y. Evolução geológica do precambriano na baixada santista. In: SIMPÓSIO REGIONAL DE GEOLOGIA, 2., 1979, Rio Claro. Atas... Rio Claro: SBG, 1979. p. 31-45. v. 1.

CHIODI FILHO, C.; CHIEREGATI, L. A.; THEODOROVICZ, A. M. G.; THEODOROVICZ, A.; MENEZES, R. G.; RAMALHO, R.; BATOLLA Jr., F. Geologia e recursos minerais das folhas de Natividade da Serra e Caraguatatuba. In: JORNADA SOBRE A CARTA GEOLÓGICADO ESTADO DE SÃO PAULO EM 1:50 000, 1., 1983, São Paulo. Atas... São Paulo: Pró-Minério, IPT, 1983. p. 8-29.

CONDIE, K. C. Plate tectonics and crustal evolution. 3.ed. New York: Pergamon, 1989. 476 p.

CORDANI, U. G.; DELHAL, J.; LEDENT, D. Orogeneses superposeés dans le précambrien du Brésil sud-oriental (états du Rio de Janeiro et de Minas Gerais). Revista Brasileira de Geociências, v. 3, n. 1, p. 1-22, 1973.

COUTINHO, J. M. V.; TASSINARI, C. C. G. The Embu and Costeiro metamorphic complexes: southeastern Brazil. In: INTERNATIONALSEMINAR NEWTRENDS INGEOLOGY, 1991. Geological Excursion... São Paulo: Instituto de
Geociências. 1991. p. 1-9.

DIAS NETO, C. M. Evolução tectono-termal do Complexo Costeiro (Faixa de Dobramentos Ribeira) em São Paulo. 2001. 160 f. Tese (Doutoramento) - Instituto de Geociências, Universidade de São Paulo, São Paulo, 2001.

DIAS NETO, C. M.; FONSECA, P. E.; MUNHÁ, J.; EGYDIO SILVA, M.; RIBEIRO, A. A estrutura em flor (flower structure) do Complexo Costeiro (Faixa Ribeira) em São Sebastião (São Paulo, Brasil). Cadernos Laboratório Xeolóxico de Laxe, La Curuña, v. 31, p. 105-125, 2006.

EBERT, H. A tectônica do sul do estado de Minas Gerais e regiões adjacentes. Brasília: DNPM/DGM, 1957. p. 97-107 (Relatório Anual do Diretor).

EBERT, H. Ocorrência de fácies granulítica no sul de Minas Gerais, e regiões adjacentes, em dependência da estrutura orogênica: hipóteses sobre sua origem. Anais da Academia Brasileira de Ciências. v. 40, p. 215-229, 1968. Suplemento.

EBERT, H. D.; HASUI, Y.; COSTA, J. B. S. O caráter transpressivo do cinturão transcorrente Rio Paraíba do Sul. In: SIMPÓSIO NACIONAL DE ESTUDOS TECTÔNICOS, 3, 1991, Rio Claro. Boletim de Resumos Expandidos... Rio Claro: SBG, 1991.p. 139-141.

EBERT, H. D.; HASUI, Y. Transpressional tectonics and strain partitioning during oblique collision between three plates in precambrian of southeast Brazil. In: HOLDSWORTH, R. E.; STRACHAN, R. A.; DEWEY, J. F. (Ed.). Continental transpressional and transtensional tectonics. London: Geological Society, 1998. p. 231-253 (Geological Society Special Publication, 135).

EBERT, H. D.; NEVES, M. A.; HASUI, I.; SZATMARI, P.; AIRES, J.R. Evolução dos cinturões de cisalhamento entre os blocos São Paulo, Vitória e Brasília através da tectônica colisional oblíqua: uma modelagem física. In: SIMPÓSIO NACIONAL DE ESTUDOS TECTÔNICOS, 4, 1993, Belo Horizonte. Anais... Belo Horizonte: SBG, 1993. p. 254-258.

EVENSEN, N. M.; HAMILTON, P. J; O’NIONS, R. K. Rareearth abundances in chondiritic meteorites. Geochemical and Coosmochemical Acta, v. 42, p. 1199-1212, 1978.

FIGUEIREDO, M.; BERMANN, M.; PENALVA, F.; TASSINARI, C. C. G. Ocorrência de "pillow lavas” no Grupo São Roque, estado de São Paulo. Ciências da Terra, v. 2, p. 6-8. 1982. 
FONSECA, M. J. G.; SILVA, Z. C. G.; CAMPOS, D. A.; TOSATTO, P. Folhas do Rio de Janeiro, Vitória e Iguape texto explicativo. Brasília: DNPM, 1979. 239 p.

HACKSPACHER, P.; DANTAS, E. L.; SPOLADORE, A; FETTERA, H.; OLIVEIRA, M. A. F. Evidence of neoproterozoic backarc basin development in the Central Ribeira Belt, southeastern Brazil: new geochronological and geochemical constrains from the São Roque-Açungui Groups. Revista Brasileira de Geociências, v. 30, n. 1, p. 110-114, 2000.

HASUI, Y.; SADOWSKI, G. R. Evolução geológica do précambriano na região sudeste do estado de São Paulo. Revista Brasileira de Geociências, v. 6, n. 3, p. 180-200, 1976.

HASUI, Y.; DANTAS, A. S. L.; CARNEIRO, C. D. R.; BISTRICHI, C. A. O embasamento pré-cambriano e eopaleozóico em São Paulo. In: MAPA geológico do estado de São Paulo. São Paulo: Pró-Minério/IPT, 1981. p. 12-45. v. 1.

IRVINE, T. N.; BARAGAR, W. R. A. A guide to the chemical classification of the common volcanic rocks. Canadian Journal of Earth Sciences, v. 8, p. 523-548, 1971.

JANASI, V. A.; ULBRICH, H. H. G. J. Inventário bibliográfico de granitos do estado de São Paulo. Boletim Instituto de Geociências, n. 11, p. 1-253, 1992. Publicação Especial.

JULIANI, C.; HACKSPACHER, P.; DANTAS, E. L.; FETTER, A. H. The mesoproterozoic vulcano-sedimentary Serra do Itaberaba Group of Central Ribeira Belt, São Paulo state, Brazil: implications for the age of the overlying Sâo Roque Group. Revista Brasileira de Geociências, v. 30, n. 1, p. 82-86, 2000.

LAZZARI, M. L. O metabasito de Pirapora do Bom Jesus. 1987. 84 f. Dissertação (Mestrado) - Instituto de Geociências, Universidade de São Paulo, São Paulo, 1987.

LE MAITRE, R. W. A classification of igneous rocks and glossary of terms. Oxford: Blackwel. 1989.193 p.

MACHADO, R.; ENDO, I. A mega estrutura em flor positiva do vale do rio Paraíba do Sul no Rio de Janeiro e suas implicações tectônicas regionais. In: SIMPÓSIO DE GEOLOGIA DO SUDESTE, 3., 1993, Rio de Janeiro. Atas... Rio de Janeiro: SBG, 1993. p. 208-213.

MAFFRA, C. Q. T. Geologia estrutural do embasamento cristalino na região de São Sebastião, SP: evidências de um domínio transpressivo. São Paulo, 2000. 113 f. Dissertação (Mestrado) - Instituto de Geociências, Universidade de São Paulo, São Paulo, 2000.

MANIAR, P. D.; PICCOLI, P. M. Tectonic discrimination of granitoids. Geochemical Society of America Bulletin, v. 101, p. 635-643, 1989.

MINIOLI, B. Determinações potássio-argônio em rochas localizadas no litoral norte do estado de São Paulo. Anais da Academia Brasileira de Ciências, v. 43, n. 2, p. 443-448, 1971.

PEARCE, J. A. Role of the sub-continental lithosphere in magma genesis at active continental margins. In: HAWKESWORTH, C. J.; NORRY, M. J. (Ed..) Continental basalts and mantle xenoliths: papers prepared for a UK volcanic studies group meeting at the University of Leicastes. Nantwich, United Kingdom, Shiva. 1983. p.230249 (Shiva in the collection: Shiva Geology Series).

ROSIER, G. F. Pesquisas geológicas na parte oriental do estado do Rio de Janeiro e na parte vizinha de Minas Gerais. Boletim. Departamento Nacional da Produção Mineral. Divisão de Geologia e Mineralogia, Rio de Janeiro, n. 222, p. 1-40, 1965.

SADOWSKI, G. R. A megafalha de Cubatão no sudeste brasileiro. Boletim do Instituto de Geociências. Série Científica, v. 22, p. 15-28, 1991.

SILVA, A. T. S. F.; ALGARTE, J. P.; CHIODI FILHO, C.; CHIODI, D. K.; FERNANDES, N. A. O Complexo Bairro do Marisco (Caraguatatuba-SP). In: SIMPÓSIO DE GEOLOGIA REGIONAL, 1., 1977, São Paulo. Anais...São Paulo: SBG, 1977. p. 74-90.

SOBREIRO NETO, A. F.; PAIVA FILHO, A.; MORTARI, J. L.; BITAR, O. Y. Geologia da Folha São Luiz do Paraitinga (SP). In: JORNADA SOBRE A CARTA GEOLÓGICA DO ESTADO DE SÃO PAULO EM 1:50.000, 1., 1983, São Paulo. Atas... São Paulo: Pro-Minério/IPT, 1983. p. 31-52.

TAYLOR, S. R.; MACLENNAN, S. M. The continental crust: its composition and evolution. Oxford: Blackwell, 1985. 312 p.

TASSINARI, C. C. G.; CAMPOS NETO, M. C. Precambrian continental crust evolution of southeastern São Paulo StateBrazil: based on isotopic evidences. Geochimica Brasiliensis, v. 2, n. 2, p. 175-183, 1988.

TASSINARI, C. C. G.; CORREIA, C. T.; MUNHÁ, J. M.; 
BARÉ, D. Relationships among charnockites and associated granites, Costeiro Complex, Central Ribeira Belt (São Paulo, Brazil). In: INTERNATIONAL GEOLOGICAL CONGRESS, 31., 2000, Rio de Janeiro. Abstracts... Rio de Janeiro: CPRM, 2000. (CD-Rom).

TASSINARI, C. C. G.; MUNHÁ, J. M. U.; RIBEIRO, A.; CORREIA, C. T. Neoproterozoic oceans in the Ribeira Belt (Southeastern Brazil) the Pirapora do Bom Jesus Ophiolitic Complex. Episodes, v. 24, n. 4, 2001.

ULBRICH, H. H. G. J.; GOMES, C. B. Alkaline rocks from continental Brazil. Earth-Science Reviews, v. 17, p. 135-154, 1981. 